\title{
A crise do tripartismo europeu \\ 0 caso da igualdade de gênero na concertação social em Portugal
}

\author{
Raquel Rego* \\ https://orcid.org/0000-0002-7342-8695 \\ Tatiana Pita* \\ https://orcid.org/0000-0003-2589-4867 \\ Cristina Nunes* \\ https://orcid.org/0000-0003-4667-7060
}

Introdução

O tripartismo tem mais de um século. Embora a Organização Internacional do Trabalho (OIT) tenha dado um incentivo com a recomendação de 1960 sobre consulta, e em 1974 publicado uma Convenção sobre consulta tripartida, são conhecidas estruturas tripartidas, por exemplo, no Reino Unido antes da Primeira Guerra Mundial (Corby \& Latreille, 2012).

A União Europeia (UE) é conhecida por promover o diálogo social como meio para alcançar mais equidade no mercado de trabalho e paz social inclusive por via tripartida. A concertação social é, assim, em muitos Estados-membro (Eurofound, 2016), a instância nacional de diálogo social, envolvendo o governo e os chamados parceiros sociais (confederações sindicais e de empregadores) na busca de consenso para as políticas públicas.

Partimos do princípio de que, se os parceiros sociais e o governo representam os interesses das mulheres, podemos esperar que os acordos da concertação social, também designados por pactos sociais, reflitam o consenso em torno da igualdade de gênero no mercado de trabalho. Com efeito, a igualdade de homens e mulheres no trabalho é promovida nos discursos das principais instituições políticas internacionais e nacionais há décadas, mesmo se as mulheres continuam a enfrentar obstáculos 
no acesso a empregos dignos ao longo da sua vida, a uma carreira profissional e a posições de chefia.

De notar que Portugal é conhecido por ter uma taxa de emprego das mulheres acima da média europeia, muitas vezes devido aos baixos rendimentos do agregado familiar, e por o sistema de relações laborais português se enquadrar no modelo do Sul da Europa. Esse modelo se carateriza por o Estado ter um papel fundamental na regulação das relações laborais, por haver um clima de grande conflitualidade entre os parceiros sociais e as estruturas de diálogo social nos locais de trabalho serem pouco relevantes (Eurofound, 2017).

O objetivo deste $\operatorname{artigo~}^{1}$ é descrever e compreender o papel da concertação social na promoção da igualdade de gênero no mercado de trabalho no caso português. Qual tem sido o papel da concertação social na promoção da igualdade de gênero no mercado de trabalho? O tema está muito ou pouco presente nos compromissos celebrados ao longo de mais de trinta anos de tripartismo? Que sentido, genérico ou preciso, assume a igualdade de gênero nos acordos assinados? Como evoluiu a igualdade de gênero na concertação social? E em função do quê variou? Estas são algumas perguntas de partida para nossa pesquisa.

Uma primeira seção do artigo é dedicada ao estado da arte. Começamos mostrando que, enquanto alguns autores destacam a importância do tripartismo para a paz e bem-estar social, outros sublinham a sua crise. Depois salientamos a extinção da política europeia de igualdade de gênero para refletir sobre os contributos, movidos pelo interesse econômico, dos parceiros sociais. Após a apresentação da metodologia usada, em que se justifica a análise temática de todos os pactos sociais assinados em Portugal em mais de trinta anos, expomos os resultados pelos principais períodos da história da concertação social portuguesa. Por fim, discutimos os resultados relacionando-os com a literatura e o contexto. Na conclusão, salientamos as principais descobertas desta pesquisa e apelamos a uma reforma da concertação social.

\section{O tripartismo como uma estratégia para o consenso}

Os sindicatos e as organizações de empregadores são os únicos grupos de interesse que alcançaram o papel de instituições parceiras do Estado a título permanente ${ }^{2}$.

1. Este artigo resulta do projeto de pesquisa "REP - Representatividade dos Parceiros Sociais e o Impacto da Governança Económica”, financiado pela Fundação para a Ciência e Tecnologia (ref.a PTDC/ soc-soc/29207/2017).

2. Em Portugal, existem quatro confederações patronais - Confederação dos Agricultores de Portugal (CAP), Confederação do Comércio e Serviços de Portugal (CCP), Confederação Empresarial de Portugal (CIP), Confederação do Turismo Português (CTP) - e duas confederações sindicais - Confederação 
Há, portanto, uma hierarquia que coloca esses grupos socioeconômicos de interesse numa posição que outros não alcançaram nas democracias liberais. O tripartismo insere-se no padrão das democracias corporativistas que se orientam pelo consenso (Lijphart, 2012). O corporatismo é, assim, a configuração de um sistema e um processo de formação de políticas, sobretudo econômicas (Corby \& Latreille, 2012). E a literatura, como mostra Lijphart (2012), tende a apoiar os sistemas corporativistas, considerando que estão associados a um melhor desempenho econômico, na medida em que a cooperação promove o desenvolvimento mais duradouro. Há uma internalização do conflito e, portanto, controle das possíveis pressões (Regini, 2003).

Esses sistemas corporativistas encontram-se em particular na Europa continental no início do século xx. Um dos pilares do chamado "modelo social europeu" foi o estabelecimento do diálogo social como um instrumento fundamental das políticas públicas europeias, nomeadamente do emprego e mercado de trabalho (Gold, Cressey \& Léonard, 2007; Hassel, 2009; Baccaro, 2015), e isso se traduz antes de mais na negociação coletiva e na concertação social. Neste contexto geográfico, “[...] o conflito de classes caracterizou os sistemas partidários e as instituições políticas de tal maneira que os parceiros sociais ganharam um status único [...]” (Hassel, 2009, p. 7). Essa preocupação europeia, em melhorar sua imagem pública através desses processos de regulação e boa governação, terá sido fomentada em particular com a crise de legitimidade democrática no início dos anos 1990 (Kröger, 2008).

Para os governos, são claros os múltiplos ganhos com o tripartismo. Como diz Hassel (2009), o que é determinante no tripartismo é o interesse do governo pelo que a situação política e macroeconômica é importante para compreender o desempenho do tripartismo (Hamman et al., 2015; Colombo, Tirelli \& Visser, 2014). Através do tripartismo, os governos mobilizam os principais implicados nas políticas, coletam informação e obtêm a sua cooperação na implementação de medidas difíceis (Baccaro, 2015), cumprem com os requisitos democráticos de transparência e prestação de contas (Donaghey \& Teague, 2005), conseguindo desse modo apoio eleitoral (Hassel, 2009). O tripartismo, consumado através dos pactos sociais, é uma forma de os governos fomentarem a paz social e atenuarem a conflitualidade social e política (Hamman et al., 2015; Colombo, Tirelli \& Visser, 2014). O tripartismo consubstanciou-se como estratégia para ultrapassar bloqueios com os parceiros sociais e foi utilizado em países como Portugal e Espanha, onde reformas trabalhistas encontraram forte resistência (Royo, 2010).

Geral dos Trabalhadores Portugueses - Intersindical Nacional (CGTP-IN), União Geral de Trabalhadores (UGT) - com assento na Comissão Permanente de Concertação Social do Conselho Económico e Social. Outras confederações existem que não mereceram esta representação institucional. 
Já os benefícios para os parceiros sociais não têm sido alvo de tão clara sistematização. De um modo geral, considera-se que a institucionalização de sua participação é uma importante prova de sua força, portanto uma fonte também de legitimidade (Hassel, 2009). Os sindicatos, em particular, para além da obtenção de supostas melhores condições para os trabalhadores, são movidos pela necessidade de se manterem como instituição relevante no sistema político (Hassel, 2009). De resto, em alguns contextos esta é a única forma de as organizações sindicais influenciarem as políticas nacionais (Donaghey \& Teague, 2005).

No Brasil, por exemplo, a Central Única dos Trabalhadores (CUT) passou de uma "CUT-movimento", nos anos 1970-80, para uma "CUT-organização", com os governos Lula e Dilma. O caso da representação institucional do Sindicato dos Metalúrgicos do ABC num fórum tripartido, no início dos anos 1990, é deste modo considerado emblemático (Ladosky \& Rodrigues, 2018). Como mostram Ladosky e Rodrigues (2018), a mudança de estratégia da CUT começa em alterações estatutárias no final dos anos 1980, mas torna-se efetiva com o novo contexto político-econômico: "Diante do contexto adverso do desemprego em patamar elevado e da dificuldade em realizar mobilizações de massa, a ação institucional acabou sendo uma 'solução' para os sindicatos permanecerem ativos e, em alguma medida, atuantes na defesa dos interesses dos trabalhadores" (2018, p. 60). Para esses autores, essa nova orientação, combinada com outras ações, como greves, não sendo apenas defensiva, levou a uma desconexão com os trabalhadores nos locais de trabalho, contribuindo assim para a crise do sindicalismo-CUT (Ladosky \& Rodrigues, 2018, p. 71). Carvalho e Costa (2018, p. 176) evidenciam ainda que o papel mais institucional do sindicalismo impulsionou o reconhecimento da forma legal das centrais sindicais e a criação do imposto sindical.

\section{A crise do tripartismo}

No entanto, o debate sobre o tripartismo é hoje também marcado pela tese de que o tripartismo está em crise (Baccaro, 2015; Corby \& Latreille, 2012). Seu declínio é evidente em alguns países membros da Zona Euro (i.e., Irlanda, Itália, Espanha e Portugal) na medida em que a resposta à crise da dívida soberana e aos programas de austeridade implementados implicou o desprezo pela consulta dos parceiros sociais. A crise do sindicalismo, traduzida num decréscimo do número de membros, não lhe foi alheia, e há quem sustente que foi mesmo responsável pelo referido desprezo dos sindicatos (Culpepper \& Regan, 2014). De fato, alguns governos europeus aprovaram reformas de modo unilateral, ignorando as estruturas e procedimentos de diálogo social (Baccaro, 2015). 
Mas a tese da crise do tripartismo vai além da crise da Zona Euro. Sanchez-Mosquera (2018) analisou a concertação social na Espanha e mostra que os sindicatos acabaram por compactuar com uma política que os enfraqueceu. A crise do tripartismo é resultado de uma abordagem neoliberal ampla e abrange diversos países. Também na Alemanha, por exemplo, foram adotadas reformas sem envolvimento dos sindicatos (Baccaro, 2015). Há ainda evidência de que a crescente jurisdificação das relações de emprego conduz à rejeição de tribunais tripartidos, por exemplo, no Reino Unido (Corby \& Latreille, 2012).

O tripartismo instituiu-se como uma forma de dar "voz" a interesses e valores tendencialmente conflituantes na economia e de prover justiça processual, ou seja, envolvendo os afetados (Heckscher, 2008), mas o processo é por isso lento. A concertação social implica tempo para negociar e o apoio dos sindicatos (Regini, 2003), o que dificilmente é compatível com o entendimento da necessidade de uma intervenção rápida. Além disso, o tripartismo é predominantemente consultivo, pelo que o envolvimento dos parceiros sociais não garante a sua influência efetiva. Essa caraterística, além de desmotivar a negociação de alguns parceiros sociais (Rego et al., 2018), pode estar contribuindo para o agravamento do deficit democrático (Kröger, 2008).

\section{O desmantelamento da política de igualdade de gênero na UE}

Desde a década de 1970, o debate e as iniciativas institucionais internacionais se sucedem sobre os direitos das mulheres e a forma como estes se enquadram na própria estrutura dos direitos humanos. Mas foi nos anos 1990 que a consciencialização se tornou mais clara (CIDM, 2013). Um dos marcos históricos mais relevantes é a Conferência Internacional sobre as Mulheres, de 1995, em Pequim, por adotar a Declaração e Plataforma de Ação, identificando áreas críticas, posteriormente reavaliadas (CIDM, 2013). Neste quadro, a UE teve um papel de destaque desde o início (Jacquot, 2017), ao incluir a igualdade de gênero na Carta dos Direitos Fundamentais da UE de 2000 (Rubery, 2015) e ao integrar a eliminação das desigualdades e a promoção da igualdade entre homens e mulheres no Tratado da UE e no Tratado de Funcionamento da UE (CIG, 2015).

A política de igualdade de gênero promovida pela UE compreendia legislação antidiscriminação, ações positivas, integração da perspetiva de gênero, financiamento e programas de ação (Jacquot, 2017). No entanto, para o período que antecede a expansão das políticas de igualdade de gênero, comparando treze países da Organização para a Cooperação e o Desenvolvimento Econômico (OCDE) (1974-86), Whitehouse (1992) mostrou que não há evidência sobre a eficácia da legislação na 
melhoria da igualdade de gênero. Nesse sentido também Zartaloudis (2015), que se debruçou sobre o caso português e grego (1995-2009), sustenta que nesses dois países não havia uma preocupação com a igualdade de gênero até meados de 1990. As mudanças ocorrem sobretudo através da Estratégia Europeia de Emprego, delineada em 1997, que constituiu “[...] o principal motor das reformas da igualdade de gênero na política de emprego" (Zartaloudis, 2015, p. 531).

É assim que os regimes de gênero ${ }^{3}$ da UE passaram de um "modelo de exceção" para um "modelo antidiscriminação" e chegaram hoje a um "modelo de direitos", para usarmos a tipologia de Jacquot (2017). Como diz essa autora, se a passagem do primeiro para o segundo modelo revela uma política progressista, o último modelo evidencia a desconstrução e mesmo o desmantelamento da política de igualdade de gênero. O que está em causa, como diz, é a progressiva extinção da política de igualdade de gênero na UE, com cortes no financiamento, redução de medidas e de condições para sua implementação (Jacquot, 2017).

\section{O contributo dos parceiros sociais}

A literatura sobre o papel dos parceiros sociais na promoção da igualdade de gênero é escassa. Mas o caso francês parece confirmar a tese de retrocesso. Em 2004 foi assinado um pacto sobre "[...] diversidade e igualdade profissional entre homens e mulheres" (Garner, 2009, p. 2). E, em 2006, os parceiros sociais franceses assinaram um novo acordo sobre a diversidade, que foi estendido em 2008 a todas as empresas (Lanquetin, 2009). O paradigma conceitual parece, pois, transitar da igualdade à diversidade, em que se incluem a etnia, a idade e a deficiência.

A nível europeu, um estudo recente, de Elomäki e Kantola (2020), sustenta que os parceiros sociais europeus são atores cruciais para a promoção da igualdade de gênero e lhes atribui um triplo papel: a) influenciam os instrumentos da UE face à política de igualdade de gênero; b) moldam o significado da igualdade entre homens e mulheres; e c) participam na transformação da relação entre o econômico e o social na agenda da UE. Ao mesmo tempo, os parceiros sociais são contraditórios e têm um entendimento limitado do gênero e da igualdade, o que pode acarretar efeitos negativos para o avanço na justiça social (Elomäki \& Kantola, 2020). As autoras (2020) mostram que os temas econômicos possuem primazia na ação das confederações patronais europeias. Ao invés disso, as confederações sindicais tendem a promover

3. Seguimos o conceito de R. W. Connell, que no artigo, dos anos 1990, "The state, gender and sexual politics" sustenta que cada Estado tem um "regime de gênero" que resulta de uma ordem de gênero mais ampla da sociedade, incluindo as lutas sociais. 
a dimensão social e a se mostrar favoráveis a mudanças legislativas que incentivam a igualdade de gênero. Nesse sentido, em 2015 e 2016, as confederações patronais foram desfavoráveis a negociar alterações no quadro europeu face às licenças de maternidade e de paternidade, enquanto do lado sindical houve uma posição concordante. Mas tanto parceiros sociais sindicais como patronais tendem a economizar a igualdade de gênero, ou seja, a igualdade de gênero não é vista como um fim em si mesma.

Em suma, se o tripartismo faz parte do padrão das democracias que promovem o consenso, as caraterísticas intrínsecas do tripartismo e as políticas neoliberais para a desregulação do mercado de trabalho, esse "mantra dos novos tempos" (Rodrigues et al., 2018, p. 1), levam vários autores a falarem da crise do tripartismo. Ao mesmo tempo, os escassos estudos sobre o contributo dos parceiros sociais, nomeadamente para a igualdade de gênero, apontam para que o diálogo social seja centrado numa perspectiva econômica, empobrecendo o debate. Na UE, onde o sistema corporativista está mais desenvolvido, procede-se agora, segundo alguns autores, ao desmantelamento das políticas de igualdade de gênero.

\section{Metodologia}

O objetivo da nossa pesquisa é descrever e compreender o papel da concertação social na promoção da igualdade de gênero no mercado de trabalho partindo do caso português. Adotamos um método qualitativo, privilegiando a análise de dados secundários: os acordos tripartidos ou pactos sociais. Os pactos sociais são o produto do consenso encontrado a nível nacional e, portanto, espera-se que reflitam a convergência quanto à igualdade de gênero.

A fim de compreendermos o contributo da concertação social para as políticas de promoção de igualdade de gênero, tivemos em conta, de forma complementar, o quadro normativo diretamente relacionado com a igualdade de gênero no mercado de trabalho, quer Diretivas europeias, quer diplomas jurídicos nacionais e outros instrumentos de políticas públicas.

Analisamos tematicamente os 25 pactos sociais assinados ao longo de mais de trinta anos de tripartismo em Portugal (1984-2019), isto é, desde a criação de uma instância de concertação social, em 1984, o Conselho Permanente de Concertação Social, até aos nossos dias, já no quadro da Comissão Permanente de Concertação Social inserida no Conselho Econômico e Social (fundado em 1991) (Lima, 2000). Se por um lado temos uma análise exaustiva, por outro lado, o número de pactos é pequeno $(\mathrm{N}<30)$ pelo que vimos limitada a análise estatística.

Para a localização, codificação e quantificação das passagens relativas ao tema da igualdade de gênero, utilizamos o software MaxQda. Para a análise de conteúdo, 
estabelecemos a seguinte lista de termos de pesquisa: "mulher(es)", "homem(ns)", "gênero", "sexo", "trabalhadora", "igualdade", "diversidade", "família", "maternidade", “parentalidade”, "gravidez/grávida”, “pai(s)”. Após esse levantamento, codificamos as passagens em cinco subtemas (Tabela 1). No subtema "Proteção na Maternidade", foram incluídos segmentos de análise que dizem respeito a medidas de proteção das mulheres grávidas e mães em relação a horários ou tarefas que possam comportar riscos para a saúde, maior proteção laboral das mulheres grávidas e mães nos despedimentos etc. Em "Inserção no Mercado de Trabalho das Mulheres”, foram tidos em consideração os segmentos que correspondem a referências expressas à inserção das mulheres, genericamente. A categoria "Não discriminação" identifica os segmentos que promovem a igualdade de oportunidades ou penalizam a discriminação laboral para ambos os sexos, como a nível remuneratório. Em "Conciliação Família-Trabalho", foram igualmente agrupados os segmentos com conteúdos sobre harmonização entre a vida familiar e profissional de ambos os sexos. Por último, em “Medidas Orientadas para Homens”, consideraram-se os conteúdos que promovem medidas de igualdade de gênero em relação aos homens em particular, como "cuidar dos filhos".

\section{Resultados}

Levando em conta os 35 anos do período de observação (1984-2019), constatamos que a distribuição dos pactos sociais ao longo do tempo é irregular: por um lado, em alguns anos não são assinados pactos sociais (i.e., 1997-2000); por outro lado, há anos com diversos pactos assinados, sendo 2006 o que mais teve pactos (4). Essa irregularidade pode ser entendida como o resultado de um padrão de institucionalização da concertação social marcado por avanços e recuos (Lima e Naumann, 2011; Natali \& Pochet, 2009).

Se no total foram assinados 25 pactos sociais, só 7 fazem alguma referência à igualdade de gênero. O período com mais pactos sociais com conteúdos de igualdade de gênero são os anos 1990, estando o tema praticamente ausente dos acordos da última década (Gráfico 1).

Do ponto de vista do contexto político, observamos que os governos do Partido Socialista (PS), centro-esquerda, e os governos minoritários, independentemente da ideologia, celebraram mais pactos sociais com inclusão de referências à igualdade de gênero, o que no fundo corresponde à expectativa de um maior diálogo à esquerda. Contudo, a diferença em relação a governos liderados pelo Partido Social Democrata (PSD), centro-direita, e a governos majoritários não é significativa. No total, o PS celebrou 16 pactos sociais e o PSD apenas 7, mas só 4 e 3, respectivamente, apre- 
GRÁFICO 1

Pactos sociais e Quadro Normativo sobre Igualdade de Gênero (1984-2019)

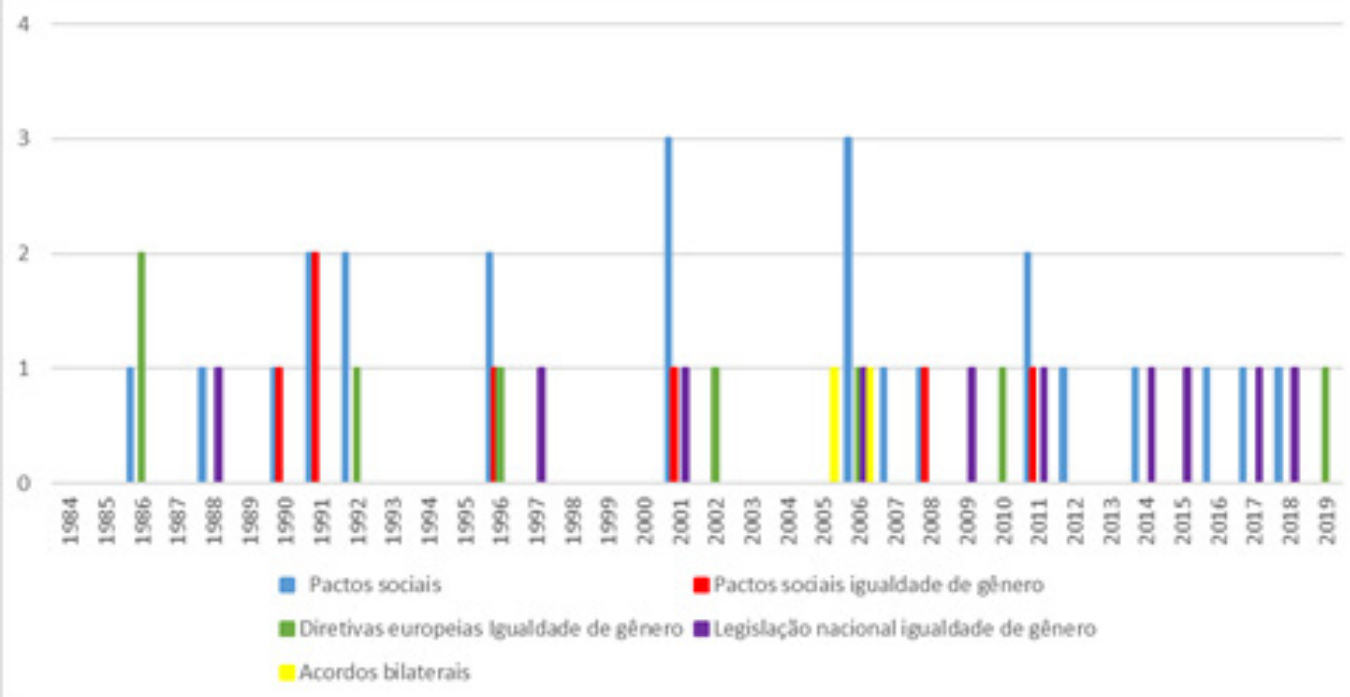

sentavam conteúdos de igualdade de gênero. De notar que o PS esteve mais tempo no governo do que o PSD e que houve sobretudo governos minoritários ao longo do período de observação (10 em 13). De notar que a promoção do tripartismo por governos majoritários foi notada como uma particularidade do país (Lima \& Naumann, 2011).

Os parceiros sociais não aderiram todos ao mesmo tempo à concertação social, nem os pactos sociais foram assinados sempre por todos, não havendo qualquer obrigação nesse sentido. Assim, a confederação sindical União Geral dos Trabalhadores (UGT) e a patronal Confederação do Comércio e Serviços de Portugal (CCP) assinaram todos os 25 pactos sociais, enquanto a confederação sindical CGTP (Confederação Geral dos Trabalhadores Portugueses), mais representativa, foi a organização que menos assinou (15 em 24). Considerando, em particular, os pactos sociais com referência à igualdade de gênero, apenas a CGTP ficou excluída de 4 dos 7. As implicações para o sucesso dos pactos e para a imagem dos parceiros sociais, por exemplo, são de avaliar, mas importa sobretudo reter que os pactos foram sendo sempre assegurados pela assinatura da UGT, a confederação sindical menos representativa e próxima do PS, o que parece confirmar a tese do empoderamento por via da institucionalização.

Os sete pactos sociais com alguma referência ao tema da igualdade de gênero totalizam 29 segmentos em que se pode encontrar o tema (Tabela 1). Esses segmentos revelam a igualdade de gênero em diversos sentidos. $\mathrm{O}$ Acordo de Concertação 
TABELA 1

Pactos sociais com referência à igualdade de gênero, por subtemas (1990-2011)

\begin{tabular}{|c|c|c|c|c|c|c|}
\hline \multirow[b]{2}{*}{ PACTOS SOCIAIS } & \multicolumn{6}{|c|}{ SUBTEMAS } \\
\hline & $\begin{array}{l}\text { Proteção na } \\
\text { Maternidade }\end{array}$ & $\begin{array}{c}\text { Inserção no Mer- } \\
\text { cado de Trabalho } \\
\text { das Mulheres }\end{array}$ & $\begin{array}{c}\text { Não Discriminação } \\
\text { (ambos os sexos) }\end{array}$ & $\begin{array}{c}\text { Conciliação } \\
\text { Família-trabalho } \\
\text { (ambos os sexos) }\end{array}$ & $\begin{array}{c}\text { Medidas } \\
\text { orientadas } \\
\text { para Homens }\end{array}$ & Total \\
\hline $\begin{array}{l}\text { Acordo Económico e } \\
\text { Social (1990) }\end{array}$ & - & 1 & - & - & 1 & 2 \\
\hline $\begin{array}{l}\text { Acordo de Política de } \\
\text { Formação Profissional } \\
(1991)\end{array}$ & - & 3 & - & - & - & 3 \\
\hline $\begin{array}{l}\text { Acordo de Segurança, } \\
\text { Higiene e Saúde no } \\
\text { Trabalho (1991) }\end{array}$ & 1 & - & - & - & - & 1 \\
\hline $\begin{array}{l}\text { Acordo de Concerta- } \\
\text { ção Estratégica (1996) }\end{array}$ & 2 & 1 & 3 & 3 & - & 9 \\
\hline $\begin{array}{l}\text { Acordo sobre Política } \\
\text { de Emprego, Mercado } \\
\text { de Trabalho, Educação } \\
(2001)\end{array}$ & - & - & 2 & 1 & - & 3 \\
\hline $\begin{array}{l}\text { Acordo para um } \\
\text { Sistema de Regulação } \\
\text { das Relações Laborais } \\
(2008)\end{array}$ & 3 & - & - & 4 & 1 & 8 \\
\hline $\begin{array}{l}\text { Acordo Tripartido para } \\
\text { a Competitividade e } \\
\text { Emprego }(2011)\end{array}$ & - & 3 & - & - & - & 3 \\
\hline Total & 6 & 8 & 5 & 8 & 2 & 29 \\
\hline
\end{tabular}

Estratégica de 1996 e o Acordo para um Sistema de Regulação das Relações Laborais de 2008 são os que reúnem mais e diversas referências.

Durante o período de observação, a produção normativa sobre igualdade de gênero, quer ao nível de Diretivas europeias, quer da produção legislativa nacional, apresenta uma distribuição mais regular do que os pactos sociais (Gráfico 1). Recorde-se que o último pacto social com conteúdos de igualdade de gênero é de 2011 e, contudo, a produção normativa vai até 2019.

1984-1990

Desde a criação da primeira instância de concertação social até ao surgimento do Conselho Econômico e Social, que coincide com a adesão de Portugal à Comuni- 
dade Econômica Europeia, período governado pelo PSD, Portugal apresenta um contexto econômico marcado pela crise e instabilidade financeira. Por exemplo, em 1984, a inflação situava-se em $28,5 \%$, e nos anos seguintes era também muito elevada (Anexo). Os conteúdos dos pactos sociais eram fortemente determinados pela conjuntura macroeconômica e pela necessidade de controlar a inflação e o déficit público, com vistas a cumprir os critérios de convergência (Natali \& Pochet, 2009). Os primeiros pactos sociais (1986-1988) centram-se assim nas políticas de rendimento e de controle da inflação e não contam ainda com a participação da principal confederação sindical, a CGTP.

Só em 1990, com o Acordo Econômico e Social-AEs, são inseridos conteúdos muito breves e genéricos à igualdade de gênero, como o "Desenvolvimento de programas que visem à inserção no mercado de trabalho dos grupos mais desfavorecidos, nomeadamente as mulheres" (AES, 1990). Há também no AES uma referência dirigida aos homens no sentido da proteção social em situação de viuvez, o que de resto parece ir ao encontro da Diretiva 86/378/CEE do Conselho, de 24 de julho de 1986, relativa à aplicação do princípio da igualdade de tratamento entre homens e mulheres aos regimes profissionais de segurança social através da "Extensão ao cônjuge sobrevivo homem do direito à pensão de sobrevivência, direito anteriormente circunscrito ao cônjuge sobrevivo mulher" (AES, 1990).

\section{$1991-2004$}

Esse período, que poderemos chamar de consolidação, pois abrange o início da concertação social enquadrada na Comissão Permanente de Concertação Social até ao acordo bilateral inédito, inicia-se com um governo majoritário do PSD que, em 1995, é substituído por um governo minoritário do ps. Uma das prioridades de ambos os governos continua a ser cumprir os critérios de convergência econômica para a integração europeia, mantendo-se como meta importante diminuir a inflação e o déficit das contas públicas (Anexo). Esse fator explica que, em 1992, o governo majoritário do PSD assine novamente um acordo dedicado às políticas de rendimento (Lima \& Naumann, 2011). A partir de 1995, o governo PS vê-se sobretudo confrontado com a necessidade de cumprir as regras econômicas europeias, o que culminará com a entrada em circulação da moeda única europeia. Essa conjuntura condiciona a assinatura dos pactos sociais, pois são necessários consensos políticos com os parceiros sociais.

Nesta segunda fase, em que se celebram vários pactos sociais (8), identificam-se mais referências à igualdade de gênero e pela primeira vez são assinados pactos que reúnem o consenso total. Os pactos sociais específicos, de 1991, sobre formação pro- 
fissional (APFP) e segurança higiene e saúde no trabalho, referem de novo as mulheres de forma genérica como um grupo que deve ser alvo de medidas de integração no mercado de trabalho, associando medidas com financiamento europeu: "A intensificação das medidas relativas ao emprego e formação de mulheres e de jovens, com destaque para as que se integram nos respectivos programas operacionais" (APFP, 1991). Esses pactos específicos decorrem, em parte, de Diretivas europeias (Diretiva 89/48/CEE e Diretiva 89/391/CEE).

Nesse período, destacam-se ainda o Acordo de Concertação Estratégica (ACE), de 1996, e, cinco anos depois, o Acordo sobre Política de Emprego, Mercado de Trabalho, Educação (2001). O ACE tem conteúdos mais precisos relativos à igualdade de gênero, e nele consta também uma referência direta à necessidade de transpor as Diretivas europeias (artigo 7 da Diretiva 92/85/CEE que estabelece que as mulheres grávidas, puérperas ou lactantes têm o direito de não exercer trabalho noturno). Esse acordo afirma também que é necessário cumprir a Diretiva 96/334/CE sobre o Acordo-quadro da licença parental celebrado pelos parceiros sociais europeus, que estabelece "prescrições mínimas para facilitar a conciliação das responsabilidades profissionais e familiares dos trabalhadores com filhos”. O período pós acordo de 1996 corresponde a uma fase de crise da concertação social em Portugal, segundo alguns autores (Lima \& Naumann, 2011; Natali \& Pochet, 2009). Divergências entre empregadores, organizações sindicais e partidos políticos inviabilizaram a implementação integral desse acordo, e os anos seguintes são caraterizados pela ausência de pactos. Em 2000, a concertação social recupera uma nova dinâmica com um papel mais ativo da CGTP (Lima \& Naumann, 2011), que assina três pactos. O pacto de 2001, sobre Política de Emprego, Mercado de Trabalho e Educação (PEM$\mathrm{TE}$ ), contém de novo orientações sobretudo genéricas sobre integração das mulheres no mercado de trabalho, procurando "Combater a discriminação, no trabalho e nas remunerações, baseada no gênero, e apoiar a inserção das mulheres na vida ativa" (PEMTE, 2001). Esses anos de retomada do dinamismo da concertação social são interrompidos em 2002 pelo governo PSD, que procura menos o diálogo com os parceiros sociais e segue uma implementação unilateral das reformas legislativas (Natali \& Pochet, 2009).

\section{5-2010}

Esse periodo, que podemos chamar de estabilização, na medida em que o acordo bilateral de 2005 comprova que a concertação social se tornou uma prática institucional regular que os próprios parceiros sociais reclamam, e que vai até ao agudizar da crise da Zona Euro, inicia-se ainda num momento de ausência de diálogo entre o governo 
PSD e as confederações sindicais. A partir de 2006, sob governação socialista, foram assinados seis pactos sociais: Acordo sobre a Fixação e Evolução da RMMG, Acordo sobre a Reforma da Segurança Social, Acordo sobre as Linhas Estratégicas de Reforma da Segurança e Acordo Visando à Formação Profissional (todos em 2006 e o último bilateral), Acordo para a Reforma da Formação Profissional (2007) e Acordo Tripartido para um Novo Sistema de Regulação das Relações Laborais, das Políticas de Emprego e da Proteção Social em Portugal (2008). Desses pactos sociais, apenas no último encontramos referências a conteúdos de igualdade de gênero. $\mathrm{O}$ pacto social de 2008 assumiu uma articulação especial entre as várias fontes normativas e revela uma maior presença de conteúdos de igualdade de gênero. $O$ pacto determina várias medidas que sugerem mudanças legislativas ao nível da proteção laboral e da parentalidade, sendo bastante preciso nos termos, como se ilustra a seguir:

Aumentar de cinco para dez dias úteis a licença a gozar obrigatoriamente pelo pai por altura do nascimento do filho, metade dos quais logo após o nascimento [assim como] Remunerar a 100\% dez dias úteis opcionais de licença, a gozar pelo pai em simultâneo (AT 2008).

Apesar de o pacto social não o referir, os conteúdos parecem decorrer do quadro normativo europeu mais uma vez. A Diretiva 2006/54/CE estabelece “[...] o princípio da igualdade de oportunidades e igualdade de tratamento entre homens e mulheres em domínios ligados ao emprego e à atividade profissional". Importa notar que algumas das propostas do pacto social terão sido introduzidas posteriormente na revisão do Código do Trabalho de 2009. Mas essa alteração no Código do Trabalho refere a Diretiva europeia, e não o pacto social. Contudo, o Decreto-lei n. ${ }^{\circ}$ 91/2009, que estipula o regime jurídico de proteção social na parentalidade, faz referência ao pacto social, no seu preâmbulo. Esse período é, de resto, marcado pela produção de outras leis nacionais relevantes para a igualdade de gênero no mercado de trabalho.

\section{1-2014}

O periodo de exceção, ou seja, de intervenção das instituições supranacionais como resultado do Memorando de Entendimento, mostra ainda assim que os problemas econômicos influenciam a assinatura de pactos sociais e contribuem para os governos procurarem o apoio dos parceiros sociais. Nesse período, que cobre o tempo da crise da dívida soberana, a taxa de desemprego chega a atingir 16,2\% (Anexo), representando o valor mais elevado desde 1984. Nesses anos, foram assinados quatro acordos em Portugal: Declaração Conjunta de um Acordo Tripartido para a Competitividade (2011), Acordo Tripartido para a Competitividade e o Emprego 
(2011), Compromisso para a o Crescimento, Competitividade e Emprego (2012) e o Acordo Relativo à Atualização da Retribuição Mínima Mensal (2014). Os acordos de 2011 são antecedidos de uma greve geral em 2010, que reuniu de forma inédita as duas confederações sindicais (UGT e CGTP). Nesse período, o governo minoritário PS enfrenta forte agitação social e política devido à implementação das medidas de austeridade do Iv Plano de Estabilidade e Crescimento. Com esses pactos, o governo procura reforçar seu apoio junto das organizações sindicais e diminuir a contestação social (Lima e Artiles, 2011). Somente o Acordo Tripartido para a Competitividade e Emprego-ATCE (2011) contém algumas considerações sobre os temas da igualdade de gênero, dirigidas ao mercado de trabalho e aos níveis de desemprego causados pelo impacto da crise econômica. Observa-se uma preocupação com o desemprego nas mulheres, mas regressa-se a uma referência genérica e breve ao tema:

Portugal, assim, precisa de aumentar a competitividade das empresas e de combater o desemprego, do qual resultam impactos sociais e económicos muito negativos, em especial nos grupos dos jovens e das mulheres [...] tendo em conta o nível de desemprego, especialmente preocupante entre as mulheres (ATCE, 2011).

Os dois últimos pactos (2012 e 2014) são assinados sob uma conjuntura de crise econômica e social e durante a presença da Troika (Fundo Monetário Internacional-FMI, o Banco Central Europeu-BCE e a Comissão Europeia-CE) no país.

\section{5-2019}

No período de retomada da concertação social como prática democrática, os indicadores econômicos apresentam uma evolução positiva face ao período anterior. Os níveis de inflação, de déficit orçamental e de desemprego decrescem consideravelmente, assim como a contestação social, medida pelo número de greves (Anexo). Nenhum dos três pactos sociais celebrados pelo governo PS no último período de nossa observação faz referência à igualdade de gênero. Trata-se de: Acordo à Aplicação da Retribuição Mínima Mensal Garantida (RMMG) (2016), Compromisso Tripartido para um Acordo de Concertação de Médio Prazo (2017) e Combater a Precariedade e Reduzir a Segmentação Laboral (2018). Mas, nesse período, continua a ser publicada legislação no âmbito da igualdade de gênero, destacando-se a Lei n. ${ }^{\circ}$ 60/2018 que "[...] aprova medidas de promoção da igualdade remuneratória entre mulheres e homens por trabalho igual ou de igual valor".

Em suma, as referências à igualdade de gênero nos pactos sociais em Portugal são escassas e tendencialmente genéricas. Os subtemas mais objeto dos pactos sociais 
foram a inserção das mulheres no mercado de trabalho e a conciliação da vida familiar e profissional para ambos os sexos. A igualdade de gênero foi relevante sobretudo no ACE de 1996 e no acordo tripartido de 2008, assinados por governos Ps. Em ambos os casos há referência a Diretivas europeias, e os conteúdos são precisos e surgem também em legislação nacional. A produção legislativa sobre igualdade de gênero decorre em grande medida do quadro normativo europeu, havendo raramente articulação de conteúdos com os pactos sociais. Quer governos do PS quer do PSD, portanto mais à esquerda ou mais à direita, promoveram a concertação social, embora com ligeiro domínio do PS. O diálogo social foi viabilizado sobretudo graças à disponibilidade da UGT, que assina desde o primeiro momento, sem a CGTP na concertação social, e mesmo em período de intervenção da troika.

\section{Discussão}

Em Portugal, diversos autores se têm debruçado sobre a igualdade de gênero no mercado de trabalho, nomeadamente nas assimetrias salariais (Casaca, 2013; Casaca \& Perista, 2017), na divisão sexual do trabalho e políticas de emprego (Ferreira, 2010), no equilíbrio entre a vida profissional e familiar (Amâncio, 2007; Cunha \& Atalaia, 2019). Mas são escassos os estudos sobre o sistema de relações laborais na perspetiva do gênero ou que envolvam uma análise do papel dos parceiros sociais na promoção da igualdade de gênero.

Uma das exceções é o trabalho de Ferreira (2002), que na viragem do século mostrava como historicamente as organizações sindicais começaram por excluir a filiação de mulheres e foram depois aderindo a uma lógica de inclusão, mas não numa posição de igualdade face aos homens. A autora sustenta que as atitudes dos sindicatos contribuíram para práticas segregadoras das mulheres no mercado de emprego, nomeadamente através de convenções coletivas de trabalho que perpetuavam as diferenças salariais entre homens e mulheres (Ferreira, 2002). Uma segunda exceção na literatura cabe a Cerdeira que, em 2009, publica o que julgamos ser o único estudo que integra a igualdade de gênero na análise da concertação social. Cedeira conclui que a presença do tema é pouco mais do que simbólica. A autora justifica esse resultado com o que chama de "fraquezas" que afetam o sistema de relações laborais: a crise econômica, que impediria um alargamento dos cadernos reivindicativos; a negociação centralizada, que dificultaria a alteração efetiva de remunerações de base; o tom conflitual das relações laborais que as fazem tender para um centramento na revisão da tabela salarial e persistir na divisão sindical.

Uma análise atenta dos pactos sociais permite-nos ver, primeiro, que a referência à igualdade de gênero reflete diferentes paradigmas concetuais ao longo do tempo. Há 
nos primeiros segmentos identificados nos pactos sociais sobre igualdade de gênero um claro centramento na mulher enquanto mãe ou grávida, notando-se, a partir de meados de 1990, a introdução da conciliação vida familiar-privada, seguindo o que Zartaloudis considerou "um mantra" da estratégia europeia de emprego (2015, p. 534). Mais tarde, a inclusão de medidas direcionadas para os homens no tema da igualdade de gênero pode ser interpretada como uma abordagem mais ampla da igualdade, mas o número de segmentos é extremamente escasso.

Em segundo lugar e ao contrário do que alguns autores sustentam para a Europa (Jacquot, 2017), pela análise dos pactos sociais portugueses, não parece haver um "desmantelamento" da igualdade de gênero. Contudo, o tema nunca foi central em nenhum acordo nem surge como resultado de aprendizagem dos próprios parceiros sociais, ou iniciativa. Ao contrário de Jacquot (2017), não detectamos a substituição de uma abordagem concetual centrada na igualdade de gênero para um paradigma da diversidade, porventura porque em Portugal não se tem dado atenção institucional a grupos étnicos, de imigrantes e outros, que pudessem caber com o grupo das mulheres no paradigma da diversidade.

Em terceiro lugar, se a influência do quadro normativo europeu (e de "mulhercratas" - Zartaloudis, 2015) parece fundamental para as políticas nacionais de igualdade de gênero, o nosso estudo mostra que essa influência também se faz nos escassos conteúdos sobre igualdade de gênero nos pactos sociais. Portugal fez progressos legislativos notáveis no que respeita à igualdade de gênero no mercado de trabalho (Monteiro \& Ferreira, 2016), mesmo se a implementação de políticas públicas pela igualdade de gênero não tem acompanhado a elevada participação das mulheres portuguesas no mercado de trabalho (Távora \& Rubery, 2013). Ora, esses progressos legislativos estão associados à necessidade de transpor Diretivas europeias. De resto, vários autores afirmavam já que a concertação social sempre foi influenciada pelas exigências e condicionamentos do processo de integração europeia (Lima \& Naumann, 2011; Natali \& Pochet, 2009; Sousa, 2009).

Em quarto lugar, no que diz respeito aos governos, verificamos que não há uma clara associação da iniciativa de concertação social a um partido líder de governo nem a determinada configuração do governo. Apesar dos governos do Ps, de centro-esquerda ou mesmo de esquerda (atendendo a que entre 2015-2019 o governo teve o apoio parlamentar dos partidos à esquerda), terem negociado pactos sociais com mais referências à igualdade de gênero, não há uma diferença significativa. $\mathrm{O}$ mesmo sucede com os governos maioritários e minoritários; isto é, se num primeiro momento se pode esperar que os minoritários tenham tendido a celebrar mais compromissos sobre igualdade de gênero para fortalecer a sua posição, não encontramos diferenças significativas. Isso não significa que tenhamos evidência que ponha em causa o que 
alguns autores (Almeida et al., 2016; Sousa, 2009; Costa, 1994) sustentam, ou seja, que "[...] existe um forte pendor para a instrumentalização governamental da concertação social" (Sousa, 2009, p. 3), ou que partidos mais à esquerda tendam mais ao diálogo social e à valorização dos parceiros sociais, nomeadamente sindicais, mas que ela não é percebida na nossa análise longitudinal e no tema da igualdade de gênero.

Em síntese, a introdução do tema da igualdade de gênero nos pactos sociais é escassa, genérica e influenciada pelo quadro europeu. Nossa análise dos pactos sociais mostra que não existe uma abordagem da igualdade de gênero nos mais de trinta anos de concertação social que a considere central ou aprofunde; pelo contrário, mostra que ela está longe de ser uma prioridade, indo ao encontro da literatura (Cerdeira, 2009; Zartaloudis, 2015). A concertação social parece ter sido palco de consenso dos parceiros sociais em torno da economia, motivada numa primeira fase pela integração europeia, união monetária, depois pela crise econômica de 2008 e finalmente pela implementação de medidas de austeridade. A igualdade de gênero, apesar do consenso que poderia ser atestado em discursos e documentos de todos os parceiros sociais e seguramente nas orientações internacionais de agências públicas, nunca se revelou uma oportunidade de consenso e iniciativa nacional.

Daqui resulta também que valerá a pena explorar a pista de um sistema de relações laborais pouco disponível para inovar. Tal como valerá a pena explorar a pista sobre a falta de representatividade dos parceiros sociais, pois as suas caraterísticas revelam uma representação de mulheres em posições de tomada de decisão ainda muito aquém da igualdade, como indicam os dados do European Institute for Gender Equality-Eige. Segundo Almeida e colaboradores (2016), a concertação social está provida de "entorses" desde a sua origem. Questionada por diversos autores (Costa, 1994; Lima \& Naumann, 2011; Sousa, 2009), a concertação social é em todo caso um compromisso democrático liderado pelo governo, não obrigando a qualquer monitorização ou implementação. A concertação social não é eficaz e, por isso, impõe-se uma reforma no sentido de responsabilizar mais os parceiros sociais envolvidos.

\section{Conclusão}

A análise dos pactos sociais assinados ao longo de mais de trinta anos de concertação social em Portugal sob a perspetiva da promoção da igualdade de gênero mostra que o tema, que esperávamos fosse consensual dentro do domínio das políticas econômicas, é irrelevante. A concertação social tem um papel muito pouco significativo nas políticas de igualdade de gênero e, quando existe alguma referência, o papel das Diretivas europeias é preponderante. Ora esta conclusão deixa-nos alguma inquietação, pois, se hoje há um desmantelamento das políticas de gênero na Europa, como 
defende Jacquot (2017), e a concertação social não é proativa, devemos esperar que a igualdade de gênero sofra um retrocesso entre nós. Assim, a reforma da concertação social parece justificada desde logo porque há evidência empírica de que os parceiros sociais responsáveis pela regulação de mercado de trabalho não estão a lidar com o desafio que é a promoção da igualdade de gênero.

As conclusões da nossa pesquisa parecem reforçar a tese de que as demandas políticas e econômicas se têm mantido como predominantes na concertação social, delegando para segundo plano dimensões sociais e de valores, assim como as críticas que têm sido tecidas à concertação social e que dão conta de que o tripartismo, estando em crise (Baccaro, 2015; Corby \& Latreille, 2012), necessita de ser reformado. Para cumprir o papel que efetivamente tem ao seu alcance, a sua missão de envolvimento dos principais grupos de interesse socioeconômicos nas políticas públicas, a concertação social requer um funcionamento que responsabilize os parceiros sociais. Por ora, os acordos assinados nesse órgão consultivo não têm consequências vinculativas, por exemplo na negociação coletiva, nem nunca foram estabelecidas metas ou avaliações do seu impacto. Uma reforma da concertação social é, pois, necessária para manter os interesses conflituais em torno do trabalho dentro do sistema democrático e efetivar a participação democrática (Kröger, 2008).

\section{Referências bibliográficas}

Almeida, João Ramos de et al. (2016), "Concertação social: A atividade da CPCS de 2009 a 2015 - Ecos das políticas europeias". Cadernos do Observatório sobre Crises e Alternativas. Coimbra, CES.

AmÂncio, Lígia. (2007), "Género e divisão do trabalho doméstico - O caso português em perspectiva”. In: WALL, Karin \& AMÂNCIO, Lígia (orgs.). Familia e género em Portugal e na Europa. Lisboa, Imprensa de Ciências Sociais, pp. 181-209.

At 2008, Acordo Tripartido para um Novo Sistema de Regulação das Relações Laborais, das Políticas de Emprego e da Proteção Social em Portugal. (25 jun. 2008), Lisboa, Ministério do Trabalho e da Solidariedade Social.

Atce 2011, Acordo Tripartido para a Competitividade e Emprego (22 mar. 2011). BACCARO, Lucio. (2015), “Labor market adjustment in Europe: farewell to social concertation?”. Seminar on International Comparative Analysis of Labor Market Reforms.

Carvalho, Fernanda Forte \& Costa, Hermes Augusto. (2018), “A relação do sindicalismo CUT com o governo: dilemas e perspectivas (2003-2016)". Política \& Trabalho - Revista de Ciências Sociais, 49: 170-187.

CASACA, Sara Falcão. (2013), "As novas dinâmicas laborais e os desafios da articulação com a vida familiar". Sociologia, Problemas e Práticas, Lisboa, 72: 31-52, maio. 
Casaca, Sara Falcão \& Perista, Heloísa. (2017), "Como explicar o persistente diferencial salarial em desfavor das mulheres? Um contributo com base nas dinâmicas laborais recentes em Portugal”. Socius/CSG Working Papers. Lisboa, Iseg.

Cerdeira, Maria da Conceição. (maio 2009), "A perspectiva de género nas relações laborais portuguesas". Sociologia, Problemas e Práticas, Lisboa, 60: 81-103.

Cinm. (2013), Estratégias internacionais para a igualdade de género: a Plataforma de ação de Pequim (1995-2005). Lisboa, CIG.

Cig. (2015), Igualdade de género em Portugal. Lisboa, Cig.

Colombo, Emilio, Tirelli, Patrizio \& Visser, Jelle. (2014), "Reinterpreting social pacts: theory and evidence". Journal of Comparative Economics, 42: 358-374.

Corby, Susan \& Latreille, Paul. (mar. 2012), “Tripartite adjudication: an endangered species”. Industrial Relations Journal, Oxford, 2 (43): 94-109.

Costa, Hermes. (1994), “A construção do pacto social”. Revista Crítica de Ciências Sociais, Coimbra, 39: 119-146.

Culpepper, Pepper \& Regan, Aidan. (2014), “Why don't governments need trade unions anymore? The death of social pacts in Ireland and Italy". Socio-Economic Review, 4 (22): 723-745.

Cunha, Vanessa \& Atalaia, Susana. (2019), “The gender(ed) division of labour in Europe patterns of practices in 18 Eu countries". Sociologia, Problemas e Práticas, Lisboa, 90: 113-137.

Donaghey, Jimmy \& Teague, Paul. (2005), “The persistence of social pacts in Europe”. Industrial Relations Journal, Oxford, 6 (36): 478-493.

ElomäKI, Anna \& Kantola, Johanna. (2020), "European social partners as gender equality actors in EU social and economic governance. JCMS: Journal of Common Market Studies, $4(58): 1-17$.

EUROFOUND. (2016), The concept of representativeness at national, international and European level - Annexes. Luxembourg, Publications Office of the European Union.

EUROFOUND. (2017), Mapping varieties of industrial relations: Eurofound's analytical framework applied. Luxembourg, Publications Office of the European Union.

Ferreira, Vírginia. (2010), A igualdade de mulheres e homens no trabalho e no emprego em Portugal: Politicas e Circunstâncias. Lisboa, Estudos 7, Comissão para a Igualdade no Trabalho e no Emprego.

Ferreira, Virgínia. (2002), "O efeito Salieri: O sindicalismo perante as desigualdades entre mulheres e homens no emprego”. Revista Critica de Ciências Sociais, Coimbra, 62: 121-148.

GARnER, Hélène. (2009), "Quelle est la place du genre dans les accords sur la diversitée?. Colloque "Genre et Diversité en Gestion”.

GolD, Michael et al. (2007), "Whatever happened to social dialogue? From partnership to managerialism in the EU employment Agenda". European Journal of Industrial Relations, 1 (13): 7-25. 
Hamman, Kerstin et al. (2015), "Sharing the rewards, dividing the costs? The electoral consequences of social pacts and legislative reform in Western Europe". West European Politics, 38 (1): 206-227.

Hassel, Anke. (2009), "Policies and politics in social pacts in Europe". European Journal of Industrial Relations, 1 (15): 7-26.

HeCKsCHer, Charles. (2008), “The evolution of stakeholder regimes: beyond neocorporatism”. In: Blyton, P., Bacon, N., Fiorito, J. \& Heery, J. (orgs.). The sage handbook of industrial relations. Londres, Sage Publications.

JACQUOT, Sophie. (2017), "A policy in crisis. The Dismantling of the EU Gender Equality Policy". In: Kantola, J. \& Lombardo, E. (orgs.). Gender and the economic crisis in Europe. Switzerland, Palgrave Macmillan.

KRÖGER, Sandra. (2008), "Nothing but consultation. The place of organised civil society in EU policy-making across policies”. European Governance Papers (Eurogov).

LAdosky, Mario Henrique Guedes \& Rodrigues, Iram Jácome. (2018), "A cut e o sindicalismo brasileiro nos anos recentes: limites e possibilidades”, Tempo Social, 30 (1), 53-76. Disponível em https://doi.org/10.11606/0103-2070.ts.2018.138079.

Lanquetin, Marie-Thérèse. (2009), “Égalité, diversité et... discriminations multiples”. Travail, Genre et Sociétés, 1 (21): 91-106.

Lijphart, Arend. (2012), Patterns of democracy: Government forms and performance in thirty-six countries. New Haven, Yale University Press.

Lima, Maria da Paz \& Artiles, Antonio. (2011), “Crisis and trade union challenges in Portugal and Spain: between general strikes and social pacts”. Transfer, 17 (3): 387-402.

Lima, Maria da Paz \& Naumann, Reinhard. (2011), "Portugal: From broad strategic pacts to policy-specific package agreements". In: Avdagic, S.; Rhodes, M. \& Visser, J. (eds.). Social pacts in Europe: Emergence, evolution and institutionalization. Oxford, University Press.

Lima, Marinús Pires de. (2000), "Reflexões sobre a negociação colectiva e a concertação social em Portugal”. In: PresidênCia Da República (org.). A reforma do pacto social. Lisboa, InCM.

Monteiro, Rosa \& Ferreira, Vírginia. (2016), “Women's movements and the State in Portugal: a State feminism approach". Sociedade e Estado, 2 (31): 459-486.

Natali, David \& Pochet, Philippe. (2009), “The evolution of social pacts in the EMU era: What type of institutionalization?”. European Journal of Industrial Relations, 15 (2): 147-166.

REgINI, Mario. (2003), “Tripartite concertation and varieties of capitalism”. European Journal of Industrial Relations, 3 (9): 251-263.

Rego, Raquel et al. (2018), "The crisis impact on the political discourse of Portuguese social partners". In: Loвo, Marina Costa; SIlva, Filipe Carreira \& Zú Quete, José Pedro (orgs.). In changing societies: Legacies and challenges. Vol. II. Citizenship in Crisis. Lisboa, Imprensa de Ciências Sociais. 
Rodrigues, Iram Jácome et al. (2018), “Apresentação - Trabalho e acção sindical em tempos difíceis”. Tempo Social, São Paulo, 30 (1): 1-7.

Royo, Sebástian. (2010), “A new century of corporatism? Corporatism in Spain and Portugal”. West European Politics, 25 (3): 77-104.

Rubery, Jill. (2015), "Austerity and the future for gender equality in Europe". Industrial and Labor Relations Review, 4 (68), 715-741.

SAnchez-Mosquera, Marcial. (2018), "Trade unionism and social pacts in Spain in comparative perspective. European Journal of Industrial Relations, 1 (24): 23-28.

Sousa, Henrique. (2009), "Há futuro para a concertação social? Os sindicatos e a experiência do modelo neocorporativo em Portugal”. Configuraçôes - Revista de Sociologia, Porto, 5/6: 1-37.

TÁvora, Isabel \& RuBERY, Jill. (2013), "Female employment, labour market institutions and gender culture in Portugal”. European Journal of Industrial Relations, 3 (19): 221-237.

Whitehouse, Gillian. (1992), "Legislation and labour market gender inequality: an analysis of OECD countries". Work, Employment \& Society, 65 (6): 65-86.

Zartaloudis, Sotirios. (2015), "Money, empowerment and neglect - the europeanization of gender equality promotion in Greek and Portuguese employment policies. Social Policy and Administration, 4 (49): 530-547. 


\section{Anexo}

Governos, indicadores econômicos e sociais (1984-2019)

\begin{tabular}{|c|c|c|c|c|c|}
\hline Ano & Partido do Primeiro-Ministro* & Tipo de Governo & Taxa de Inflação & Taxa de desemprego & Número de Greves \\
\hline 1984 & PS & minoritário & 28,5 & 8,2 & n.d. \\
\hline 1985 & PS & minoritário & 19,5 & 8,5 & n.d. \\
\hline 1986 & PSD & minoritário & 12,6 & 8,3 & 363 \\
\hline 1987 & PSD & minoritário & 9,7 & 6,8 & 213 \\
\hline 1988 & PSD & maioritário & 9,9 & 5,6 & 181 \\
\hline 1989 & PSD & maioritário & 12,5 & 5,0 & 307 \\
\hline 1990 & PSD & maioritário & 13,6 & 4,6 & 271 \\
\hline 1991 & PSD & maioritário & 11,8 & 4,1 & 262 \\
\hline 1992 & PSD & maioritário & 9,6 & 4,1 & 409 \\
\hline 1993 & PSD & maioritário & 6,8 & 5,5 & 230 \\
\hline 1994 & PSD & maioritário & 5,4 & 6,8 & 300 \\
\hline 1995 & PSD & maioritário & 4,2 & 7,1 & 282 \\
\hline 1996 & PS & minoritário & 3,1 & 7,2 & 274 \\
\hline 1997 & PS & minoritário & 2,3 & 6,7 & 265 \\
\hline 1998 & PS & minoritário & 2,6 & 4,9 & 227 \\
\hline 1999 & PS & minoritário & 2,3 & 4,4 & 200 \\
\hline 2000 & PS & minoritário & 2,9 & 3,9 & 250 \\
\hline 2001 & PS & minoritário & 4,4 & 4,0 & 208 \\
\hline 2002 & PSD & minoritário & 3,6 & 5,0 & 250 \\
\hline 2003 & PSD & minoritário & 3,2 & 6,3 & 170 \\
\hline 2004 & PSD & minoritário & 2,4 & 6,6 & 122 \\
\hline 2005 & PS & maioritário & 2,3 & 7,6 & 126 \\
\hline 2006 & PS & maioritário & 3,1 & 7,6 & 155 \\
\hline 2007 & PS & maioritário & 2,5 & 8,0 & 99 \\
\hline 2008 & PS & maioritário & 2,6 & 7,6 & n.d. \\
\hline 2009 & PS & maioritário & $-0,8$ & 9,4 & n.d. \\
\hline 2010 & PS & minoritário & 1,4 & 10,8 & 123 \\
\hline 2011 & PS & minoritário & 3,7 & 12,7 & 88 \\
\hline 2012 & PSD & maioritário & 2,8 & 15,5 & 127 \\
\hline 2013 & PSD & maioritário & 0,3 & 16,2 & 119 \\
\hline 2014 & PSD & maioritário & $-0,3$ & 13,9 & 90 \\
\hline 2015 & PSD & maioritário & 0,5 & 12,4 & 75 \\
\hline 2016 & PS & minoritário & 0,6 & 11,1 & 76 \\
\hline 2017 & PS & minoritário & 1,4 & 8,9 & 106 \\
\hline 2018 & PS & minoritário & 1,0 & 7,0 & 144 \\
\hline 2019 & PS & minoritário & 0,3 & 6,5 & n.d. \\
\hline
\end{tabular}

* Em ano de eleições, considera-se o partido que permaneceu mais meses no governo. Mas, no caso de terem sido assinado pactos, considera-se o partido que os assinou. ${ }^{* *}$ n.d.: não disponível

Fontes: A informação sobre todos os indicadores foi extraída de https://www.pordata.pt (acedido a 15.12.2020), à exceção das variáveis Partido do Primeiro Ministro e Tipo de Governo - https://portugal.gov.pt (acedido a 15.12.2020). 


\section{Resumo}

A crise do tripartismo europeu: O caso da igualdade de gênero na concertação social em Portugal Nos sistemas corporatistas prevalecentes na UE, a concertação social é a instância que promove o consenso a nível nacional entre sindicatos, empregadores e governos. Perante a persistente desigualdade do mercado de trabalho, perguntámo-nos qual tem sido o seu contributo para as políticas de igualdade de gênero. Respondemos a esta pergunta com a análise de conteúdo dos pactos sociais assinados em Portugal ao longo de mais de trinta anos de tripartismo (1984-2019). Os resultados mostram que a igualdade de gênero tem um peso reduzido nos pactos sociais e que o quadro normativo europeu é determinante nos avanços feitos. Nosso estudo reforça assim a literatura existente que aponta para a necessidade de uma reforma do tripartismo.

Palavras-chave: Igualdade de gênero; Pactos sociais; Tripartismo; Quadro normativo; Portugal.

\section{Abstract}

The crisis of European tripartism: The case of gender equality on social concertation in Portugal Within the corporatist systems of the EU, social concertation is the body that promotes the national consensus among trade unions, employers and governments. Given the persistent inequality of the labour market, we have wondered what contribution it has been making to gender equality policies. We responded to this question by analysing the content of the social pacts signed in Portugal over more than 30 years of tripartism (1984-2019). The results show that gender equality has little weight in social pacts and that the European regulatory framework is decisive in the progress made. Our study thus reinforces the existing literature which points to the need for a reform of tripartism.

Keywords: Gender equality; Social pacts; Tripartism; Normative framework; Portugal.

Texto recebido em 26/1/2021 e aprovado em 1/3/2021.

DOI: $10.11606 / 0103-2070 . t s .2021 .181339$

RaQuel Rego é socióloga e atualmente pesquisadora no Instituto de Ciências Sociais da Universidade de Lisboa. Coordena o projeto REP-Representatividade dos parceiros sociais e impacto da governança econômica, financiado pela Fundação para a Ciência e Tecnologia - FCT (2018-2022).E-mail: raquel.rego@ics.ulisboa.pt.

Tatiana Pita é doutoranda no programa interuniversitário OpenSoc, bolsista de doutoramento da FCT, e membro da equipe do projeto REP.E-mail: tatiana.pita@ics.ulisboa.pt.

CRISTINA NUnes doutorou-se em sociologia pelo ISCTE-IUL, Instituto Universitário de Lisboa, em 2018.É atualmente pesquisadora no âmbito do projeto REP.E-mail: cristina.nunes@ ics.ulisboa.pt. 